\title{
Detection of selected agricultural pesticides in river and tap water in Letsitele, Lomati and Vals-Renoster catchments, South Africa
}

\author{
M Machete ${ }^{1 *}$ and JM Shadung ${ }^{2}$ \\ ${ }^{1}$ College of Agriculture and Environmental Sciences, University of South Africa (UNISA), Science Campus, Florida Park, South Africa \\ ${ }^{2}$ Council for Scientific and Industrial Research (CSIR), Natural Resources \& the Environment, PO Box 395, Pretoria, 0001, South Africa
}

\begin{abstract}
This paper presents the levels of detection of selected agricultural pesticides in river and tap water in the Letsitele, Lomati and Vals-Renoster catchments, South Africa. Agriculture plays a major role in the development of communities through job creation and poverty eradication. However, exposure to agricultural pesticides can result in serious human health and environmental effects. This study, therefore, identified critical areas where specific pesticides might result in high environmental and human health risks. Three water catchment areas, namely, Letsitele, Lomati and Vals-Renoster, were identified for raw and tap water analysis. The results confirmed the presence of selected agricultural pesticides: atrazine, terbuthylazine, imidacloprid, metolachlor, simazine and alachlor. Although low concentrations of most of these pesticides were detected, pesticides such as atrazine, alachlor and simazine are known for endocrine disruption. A critical finding of this study is the detection of these pesticides in tap water (drinking water) of a primary school in the Lomati catchment. This reveals a high exposure potential for human health. It is thus recommended that further research be conducted to determine the potential health risks associated with these pesticides among vulnerable communities, through epidemiological studies.
\end{abstract}

Keywords: pesticides, endocrine disruptors, environmental health risks, agriculture, water quality

\section{INTRODUCTION}

South Africa has the largest agricultural pesticide market in the sub-Saharan Africa region (Naidoo and Buckley, 2003). The South African National Department of Agriculture, Forestry and Fisheries (DAFF, 2010; 2013) registered a variety of pesticides for agricultural use during the years 2010 and 2013. Dabrowski (2015a) confirmed that more than 3000 pesticides were registered for use by the agricultural sector in South Africa in 2015. Pesticides are one of the many technologies commonly used to improve agricultural production in South Africa (Dabrowski, 2015a). In an earlier study, Maharaj (2005) raised concern about the increasing trend of pesticide use in South African agricultural production and the number of pesticides used. The primary concern of Maharaj (2005) was the deterioration in the chemical water quality of South Africa's rivers.

Agriculture is one of the key sectors of the South African economy that is relied upon for addressing the country's $26.6 \%$ and $39 \%$ unemployment and poverty rates, respectively (StatsSA, 2016). In the light of the current levels of unemployment, poverty and inequality, cessation of pesticide use is not considered an option. In contrast to the economic potential of rapid growth of the agricultural sector, the use of most agricultural pesticides presents both chronic and acute environmental and human health risks, particularly for farming communities that are vulnerable due to living in close proximity to pesticide use.

*Corresponding author, email: mtec.dr@gmail.com

Received 15 June 2017; accepted in revised form 4 October 2019
Machete (2017) points out that organic and inorganic elements or compounds of agricultural pesticides are capable of moving from a point of application into non-target environments, particularly in surface and groundwater resources. In an earlier study, Dabrowski and De Klerk (2013) found the presence of agricultural pesticides in the water resources bordering intensely farmed areas, and detected pesticides in ground, surface and drinking water. Various studies have highlighted the persistent nature, mobility and potential environmental risks associated with a number of commonly used agricultural pesticides (Schulz, 2001; Footprint, 2006; Dabrowski, 2015a; Machete, 2017).

Numerous chronic and acute environmental health risks are associated with agricultural pesticide exposure. Footprint (2006) and Schulz (2001) concur that environmental exposure to agricultural pesticides is responsible for many incidences of toxicity to aquatic organisms. For instance, chlorpyrifos and endosulfan have been detected in environmental water samples at levels that may be toxic to fish and other macro-invertebrates (Dabrowski et al., 2014). According to Hallenbeck and Cunningham-Burns (2011), agricultural pesticides contain chemical elements or compounds that are carcinogenic, teratogenic, mutagenic and endocrine disruptive to living organisms (including human beings).

In developing countries, the use of agricultural pesticides has been associated with a myriad of detrimental effects on female health (London et al., 2002). In South Africa, the consequence of pesticide exposure has been related to several human health effects such as endocrine disruption, among others (Aneck-Hahn et al., 2007; English et al., 2012). In light 
of the seriousness of the environmental health risks associated with agricultural pesticide exposure, this study aimed to determine if agricultural pesticides could be detected in river and tap water in Letsitele, Lomati and Vals-Renoster catchments, South Africa.

\section{MATERIALS AND METHODS}

This study was conducted in three farmed water catchment areas, namely, Letsitele, Lomati, and Vals-Renoster. The three catchment areas were selected due to suspected potentially high pesticide contamination.

\section{Letsitele catchment}

The Letsitele River is located in Limpopo. The river drains the Wolkberg Mountains and flows in a north-easterly direction towards the town, Letsitele, where it flows into the Letaba River. The upper reaches of the catchment mainly comprise of commercial forestry. The river passes through intensively cultivated commercial agricultural land where avocados, citrus fruit and mangoes are produced. Human settlements with domestic livestock and communal gardens occur in close proximity to these commercial agricultural areas. The towns of Khujwana and Mogoboya are adjacent to the Letsitele River near fruit orchards. The upper sections of the catchment are characterised by relatively steep slopes, resulting in a relatively high runoff potential for pesticides. The main soil type is a sandy clay loam, which has a relatively high percentage of sand and is thus susceptible to leaching agrochemicals (Dabrowski, 2015a). This study identified these fruit orchards as potential sources for pesticide spray drift towards human settlements and water sources. Thus, the catchment area and specific sites in it were selected for the purposes of tracing potential endocrine-disrupting chemicals (EDCs) in the domestic water supply.

\section{Lomati catchment}

The Lomati River is located in the eastern part of Mpumalanga, north of Eswatini and south of Mozambique. Sugarcane production is the primary agricultural activity undertaken in the surrounding areas, with a smaller proportion contributed by maize, mangoes, bananas and wheat production. The Lomati River originates in Eswatini and flows into Driekoppies Dam and then into the Komati River. Agricultural activities are generally undertaken on low to medium gradient slopes of relatively sandy soil. The mean annual precipitation for the Lomati catchment is $880 \mathrm{~mm}$ (Deksissa et al., 2003), with most rainfall occurring in the summer months between November and March.

\section{Vals and Renoster catchments}

The Vals River flows in a westerly direction from upstream of Kroonstad past Khotsong and Bothaville before entering the Vaal River. Kroonstad is located midway along the river between VL3 and VL2 and this section of the river is affected by a number of industries and point-source pollution impacts (e.g. sewage outfalls). The catchment of the Renoster River is also an intensive agricultural area, and few large towns are situated along the length of the river. The river flows northwards, entering the Vaal River upstream of its confluence with the Vals River. Relatively few large towns are located along the length of the river (Dabrowski, 2015b). Agricultural activity in the Vals and Renoster catchments consists of intensive maize production along with sorghum and sunflower production. The catchment area is predominately agricultural and is particularly flat in the lower reaches. It has a high proportion of sandy soils which are associated with increased pesticide leaching potential (Dabrowski, 2015b).

\section{Sampling}

A total of 14 water sampling points were selected across the three catchments (Table 1).

Three samples were collected from Letsitele, five from Lomati and six from Vals-Renoster (see Table 1). Four seasonal sampling sessions were conducted for each sampling point.

\section{Selection of pesticides for analysis}

Information on pesticide use per crop at a national scale (DAFF, 2013) was used to prioritise specific pesticides for testing and analysis in the 14 samples collected. Quarterly raw and tap water samples were collected and analysed to assess the presence of pesticides and their seasonal variation, if any. All raw water samples were collected in $1 \mathrm{~L}$ amber glass bottles at approximately $50 \mathrm{~cm}$ below the water surface for raw water sampling. All raw and tap water samples were transported on ice at $4^{\circ} \mathrm{C}$ until delivered to an accredited laboratory. The pesticide crop prioritisation matrix identifies atrazine, terbuthylazine, imidacloprid, metolachlor, simazine and alachlor as relatively high national priority pesticides used in agriculture. Atrazine, alachlor and simazine are among the 12 known endocrine disrupting pesticides (Footprint, 2006; McKinlay et al., 2008).

\section{Quantitative analysis of GC-MS}

Liquid-to-liquid extraction was used to extract samples, which

Table 1. Sampling points in the Letsitele, Lomati and Vals-Renoster catchments

\begin{tabular}{|c|c|c|c|c|c|c|}
\hline Catchment & & & Sampling po & ints & & \\
\hline Letsitele & $\begin{array}{l}\text { Letsitele River (LT3) } \\
23.974673^{\circ} \mathrm{S} \\
30.165144^{\circ} \mathrm{E}\end{array}$ & $\begin{array}{l}\text { Tap water at a } \\
\text { primary school (LT4) } \\
23.974653^{\circ} \mathrm{S} \\
30.164833^{\circ} \mathrm{E}\end{array}$ & $\begin{array}{l}\text { Letsitele River (LT9) } \\
23.924655^{\circ} \mathrm{S} \\
30.267180^{\circ} \mathrm{E}\end{array}$ & & & \\
\hline Lomati & $\begin{array}{l}\text { Tributary of Lomati } \\
\text { River (NK1) } \\
25.652297^{\circ} \mathrm{S} \\
31.541136^{\circ} \mathrm{E}\end{array}$ & $\begin{array}{l}\text { Lomati River (NK2) } \\
25.684586^{\circ} \mathrm{S} \\
31.538691^{\circ} \mathrm{E}\end{array}$ & $\begin{array}{l}\text { Tap water (NK3) } \\
25.672227^{\circ} \mathrm{S} \\
31.639483^{\circ} \mathrm{E}\end{array}$ & $\begin{array}{l}\text { Ngwezi River (NK4) } \\
25.449998^{\circ} \mathrm{S} \\
31.944495^{\circ} \mathrm{E}\end{array}$ & $\begin{array}{l}\text { Mzinti River } \\
\text { (NK5) } \\
25.692400^{\circ} \mathrm{S} \\
31.732693^{\circ} \mathrm{E}\end{array}$ & \\
\hline Vals-Renoster & $\begin{array}{l}\text { Tributary of Vals } \\
\text { River (VL1) } \\
27.890709^{\circ} \mathrm{S} \\
27.376506^{\circ} \mathrm{E}\end{array}$ & $\begin{array}{l}\text { Vals River (VL2) } \\
27.610978^{\circ} \mathrm{S} \\
27.102011^{\circ} \mathrm{E}\end{array}$ & $\begin{array}{l}\text { Vals River (VL3) } \\
27.490141^{\circ} \mathrm{S} \\
26.656111^{\circ} \mathrm{E}\end{array}$ & $\begin{array}{l}\text { Tributary of Renoster } \\
\text { River (RN1) } \\
27.293820^{\circ} \mathrm{S} \\
27.789787^{\circ} \mathrm{E}\end{array}$ & $\begin{array}{l}\text { Renoster River } \\
\quad \text { (RN3) } \\
27.233362^{\circ} \mathrm{S} \\
27.324581^{\circ} \mathrm{E}\end{array}$ & $\begin{array}{l}\text { Renoster River } \\
\text { (RN4) } \\
27.071720^{\circ} \mathrm{S} \\
27.044392^{\circ} \mathrm{E}\end{array}$ \\
\hline
\end{tabular}


involved collecting the organic layer; adjusting the $\mathrm{pH}$; shaking and filtering. The elution was rotary evaporated to the required final volume of $0.5 \mathrm{~mL}$ and analysed on capillary column GC-MSD for organophosphates (following the method of Dabrowski et al., 2014).

\section{RESULTS AND DISCUSSION}

\section{Letsitele catchment}

Five EDC pesticides were present at the Letsitele catchment sites (1) upstream (LT3), (2) tap at a public primary school (LT4) and

(3) downstream (LT9), as presented in Fig. 1.

The results show a high detection level of diphenylamine, imazalil, thiabendazole, imidacloprid and propiconazole in November 2011. Much higher concentrations of imazalil, thiabendazole and diphenylamine were observed, with propiconazole and imidacloprid occurring at lower concentrations. EDCs were detected in the tap water (drinking water) from a borehole at a primary school in Letsitele Furthermore, a much higher concentration of diphenylamine, imizalil and thiabendazole was detected in November 2011, with propiconazole consistently detected in the tap water at the primary school in almost all seasons, with the exception of the August and November 2012 sampling seasons. The results also show higher EDC concentration in ground water than in surface water, as seen for LT3 and LT4 samples across seasons. Consistent detection of higher levels of imidacloprid at LT9 in all seasons were also noted, as compared to its absence in LT3.

\section{Lomati catchment}

Based on the type of agricultural production and potential EDC pesticides used in the catchment area, the concentrations $(\mu \mathrm{g} / \mathrm{L})$ of selected pesticides were analysed in water samples collected from selected sites in the Lomati catchment area (Fig. 2).

The results show no detected EDCs in the June 2012

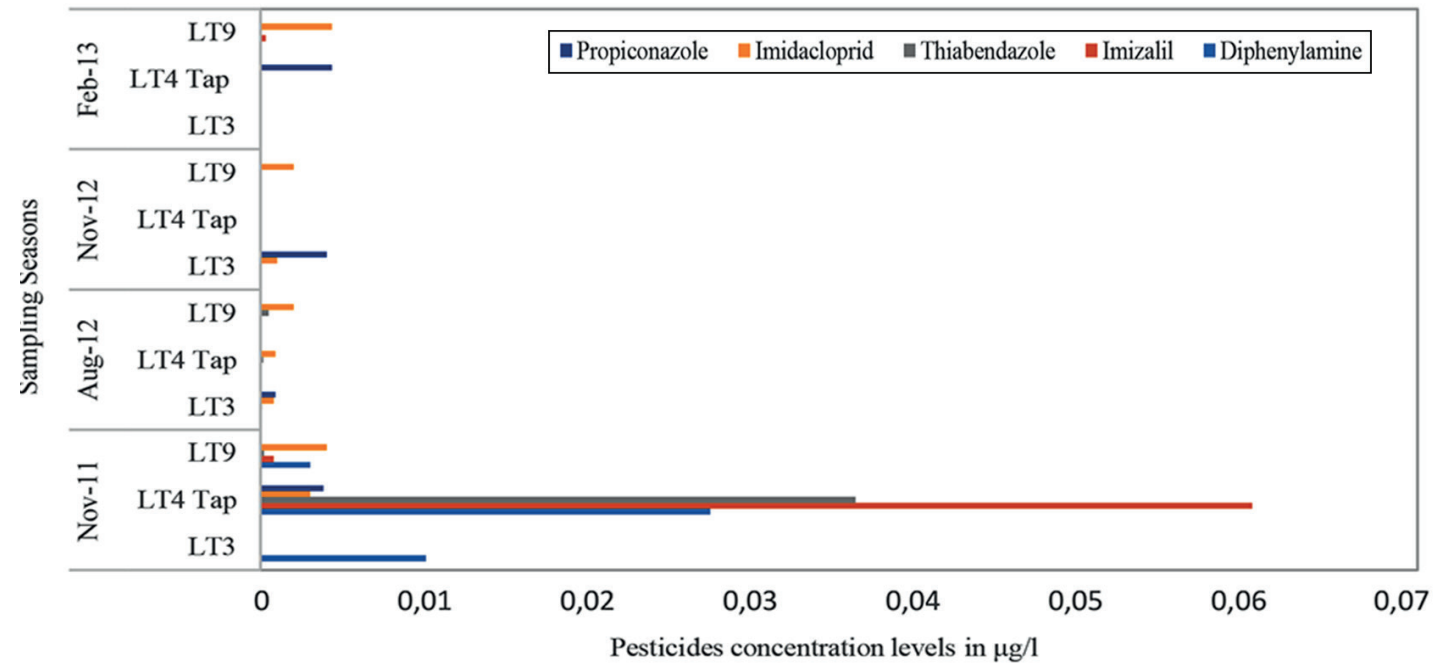

Figure 1. Seasonal levels of pesticides detected in the Letsitele catchment

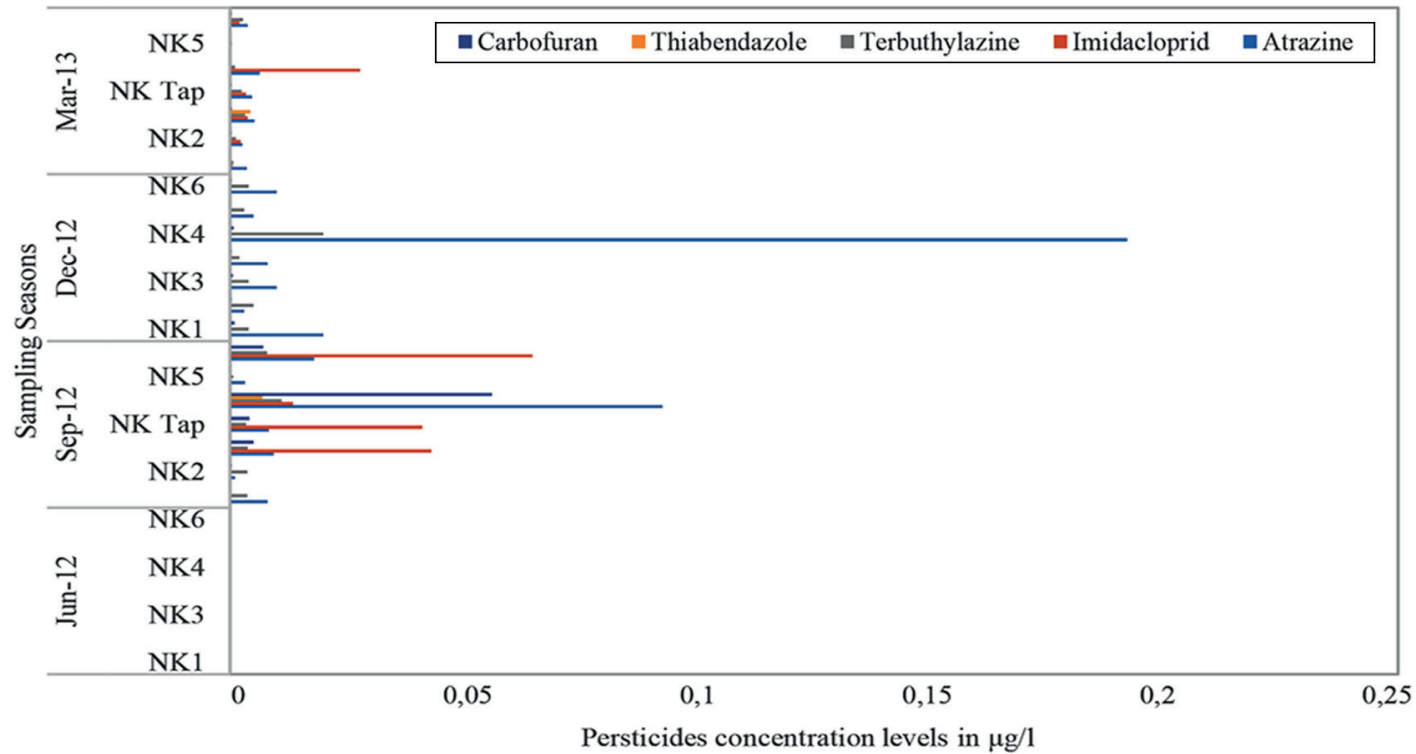

Figure 2. Concentration levels ( $\mu \mathrm{g} / \mathrm{L}$ ) of selected pesticides in the Lomati catchment 
sampling season. However, during the September and December 2012 and March 2013 sampling seasons, atrazine, imidacloprid, terbuthylazine and carbofuran were detected at varying concentrations. Atrazine was detected in all samples, despite being at low concentrations. It was noted that atrazine concentration was at higher levels in NK4 during September and December 2012 than for all other sampling sites. All the above-mentioned five pesticides were detected at NK3, NK3tap, NK4 and NK6 sampling sites. Higher concentrations of pesticides were consistently detected at NK4 throughout the sampling period when compared to the other sites. It is also noted that NK5 was the least contaminated of all sites. However, the presence of EDCs in the NK3 tap water is of serious concern, as it represents direct human exposure to the pesticides, in particular schoolchildren in the school where the tap is located and is used for drinking water supply.

\section{Vals-Renoster water catchment}

Presence and concentrations of atrazine, alachlor, imadaclopid and terbuthylazine $(\mu \mathrm{g} / \mathrm{L})$ were analysed in water samples collected from selected sites in the Vals and Renoster catchments, based on the prevailing agricultural production practices and types of pesticides used (Fig. 3).

The results confirm the presence of atrazine, alachlor, imadaclopid and terbuthylazine in different samples in all seasons in the Vals and Renoster catchments. Although not all samples had all five EDCs detected in equal frequencies and concentrations, all EDCs were detected at one or more sampling sites during each sampling season. In January and April 2013 (rainy season), the concentration levels showed an increase for atrazine, simazine and terbuthylazine. The samples from VL2 and VL3 showed consistently high concentrations of simazine, atrazine and terbuthylazine in January and April 2013, followed by RN3 in January 2013 and VL3 in April 2013. The detection and concentrations indicate a relationship between the rainy season and leaching of EDC pesticides, as found in previous studies (Schulz, 2001; Dabrowski and Schulz, 2003; Dabrowski, 2015b).

\section{CONCLUSION}

This study confirmed traces of various EDC pesticides in raw and drinking water in the Letsitele, Lomati and ValsRenoster catchment areas. Traces of pesticides in borehole and reticulated tap water samples were confirmed in Nkomati and Letsitele, respectively. The pesticides investigated are known EDCs, and were found at high concentrations in some instances. Wu et al. (2009) found that exposure to atrazine concentrations as low as $0.1 \mathrm{ppb}$ can alter the sex characteristics of male frogs, resulting in male frogs with female sex characteristics, hermaphroditism and the presence of eggs in male frog testes. The current study found much higher concentrations of atrazine and other EDCs in drinking water in this study, which presents a much higher potential of exposure and the possibility of a myriad of effects on humans and the environment (fauna and flora). The (ATSDR, 2003), found that atrazine can cause liver, kidney and heart damage in animals, and could possibly cause cancer in humans.

Maternal exposure to atrazine has been associated with low birth weights, heart, urinary and limb defects in humans. Wu et al. (2009) report that atrazine exposure can lead to adverse reproductive effects in animals and humans, even at low levels of exposure. When exposure coincides with the development of the brain and reproductive organs, the effects may be even more severe. Also of great concern is the potential for atrazine to act synergistically with other pesticides to increase their toxic effects. Fitzmayer et al. (1982) and Garry (2004) confirmed the acute toxicity effects of simazine and other EDCs on human health, particularly in children. Further studies are recommended, including epidemiological investigations to establish the prevalence of environmental health risks and specifically to establish a cause-effect relationship between human exposure to the studied pesticides and potential environmental health risks highlighted in other studies. Finally, this study also highlights the question of the efficacy of existing water treatment technologies in the study areas, due to their inability to completely eliminate EDCs during water treatment processes. This suggests the need for water treatment in the indicated areas to be investigated.

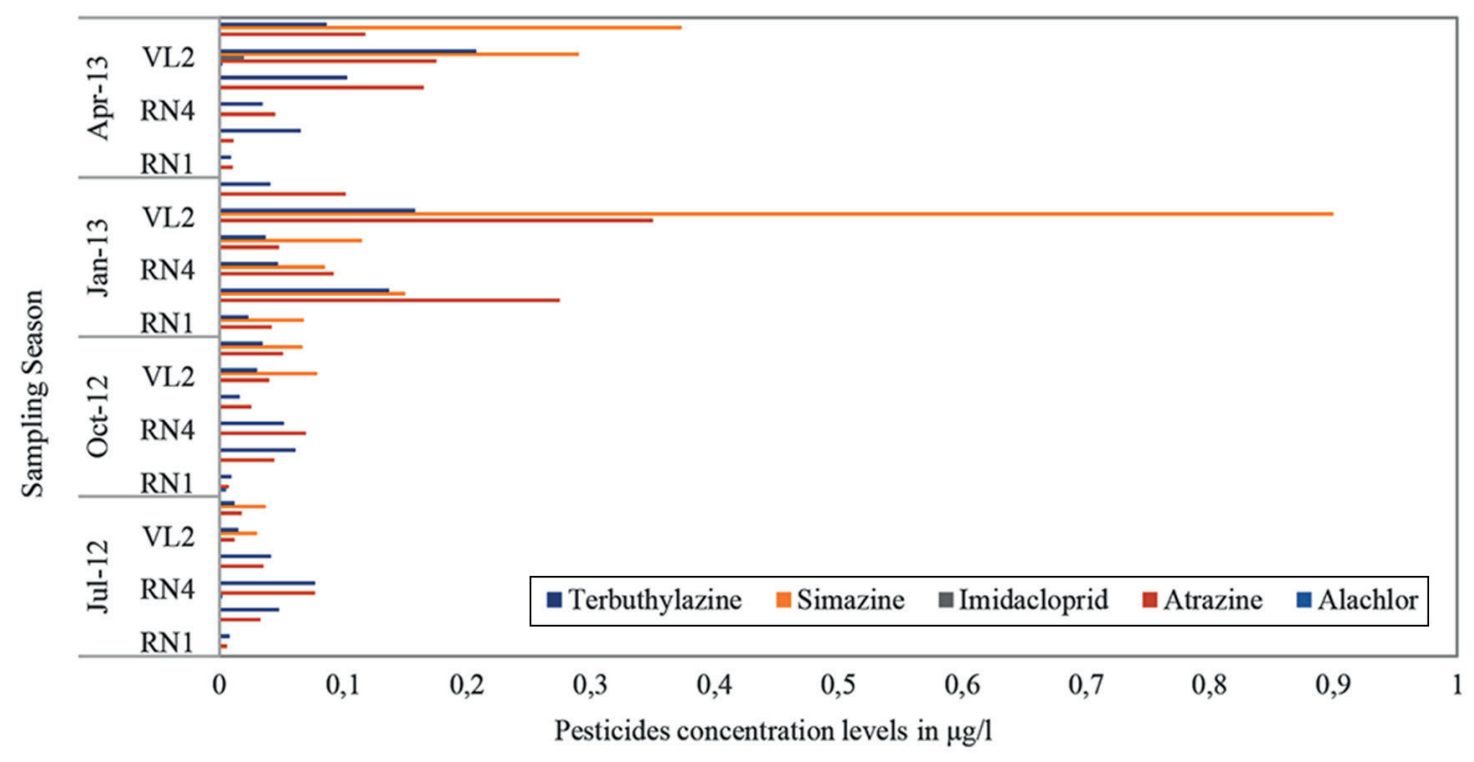

Figure 3. Concentration levels (in $\mu \mathrm{g} / \mathrm{L}$ ) of detected pesticides in the Vals and Renoster catchments 


\section{ACKNOWLEDGEMENTS}

This paper has emerged from a research project funded by the Water Research Commission (Report No. 1956/1/15), the Council for Scientific and Industrial Research (CSIR), under the Natural Resources and the Environment Business Unit. Data analysis, presentation of results, write-up and editing of this paper was sponsored by Ga-Machete Guesthouses.

\section{REFERENCES}

ATSDR (Agency for Toxic Substances and Disease Registry) (2003) Public Health Statement for Atrazine. URL: https://www.atsdr.cdc. gov/phs/phs.asp?id=336\&tid=59. (Accessed 5 June 2017).

ANECK-HAHN, NH, SCHULENBURG GW, BORNMAN MS, FARIAS P and DE JAGER C (2007) Impaired semen quality associated with environmental DDT exposure in young men living in a malaria area in the Limpopo Province, South Africa. J. Androl. 28 (3) 423-434. https://doi.org/10.2164/jandrol.106.001701

DABROWSKI JM (2015a) Development of pesticide use maps for South Africa. S. Afr. J. Sci. 111 (1-2) 07. https://doi.org/10.17159/ sajs.2015/20140091

DABROWSKI JM (2015b) Investigation of the contamination of water resources by agricultural chemicals and the impact on environmental health. Volume 1: Risk assessment of agricultural chemicals to human and animal health. WRC Report No. 1956/1/15.

DABROWSKI JM and DE KLERK LP (2013) An assessment of the impact of different land use activities on water quality in the upper Olifants River catchment. Water SA 39 (2) 231-244. https://doi. org/10.4314/wsa.v39i2.6

DABROWSKI JM and SCHULZ R (2003) Predicted and measured levels of azinphosmethyl in the Lourens River, South Africa. Comparison of runoff and spray drift. Environ. Toxic. Chem. 22 (3) 494-500. https://doi.org/10.1002/etc.5620220305

DABROWSKI JM, SHADUNG MJ and WEPENER V (2014) Prioritizing agricultural pesticides used in South Africa based on their environmental mobility and potential human health effects. Environ. Int. 62 31-40. https://doi.org/10.1016/j.envint.2013.10.001

DAFF (Department of Agriculture, Forestry and Fisheries, South Africa) (2010) Pesticide management policy for South Africa. Government Gazette No. 33899, Pretoria.

DAFF (Department of Agriculture, Forestry and Fisheries, South Africa) (2013) Trends in the agricultural sector. DAFF, Pretoria.

DEKSISSA T, ASHTON PJ and VANROLLEGHEM (2003) Control options for river water quality improvement: A case study of TDS and inorganic nitrogen in the Crocodile River (South Africa). Water SA 29 (209) 217. https://doi.org/10.4314/wsa.v29i2.4858 ENGLISH RG, PERRY M, LEE MM, HOFFMAN E, DELPORT S and DALVIE MA (2012) Farm residence and reproductive health among young boys in rural South Africa. Environ. Int. 47 73-79. https://doi.org/10.1016/j.envint.2012.06.006

FITZMAYER KM, GEIGER JG and VAN-DEN-AVYLE MJ (1982) Acute toxicity effects of simazine on Daphnia pulex and larval striped bass. Proceedings of the thirty sixth annual conference. S.E. Assoc of Fish and Wildlife Agen. 36 146-156.

FOOTPRINT (2006) Footprint Pesticide Properties Database. Database collated by the University of Hertfordshire as part of the EU-funded Footprint project (FP6-SSP-022704).URL: http://www. eu-footprint.org/ppdb.html (Accessed 7 April 2010).

GARRY VV (2004) Pesticides and children. Toxic. Appl. Pharmacol. 198 (2) 152-163. https://doi.org/10.1016/j.taap.2003.11.027

HALLENBECK WH and CUNNINGHAM-BURNS KM (2011) Pesticides and Human Health. Springer, London. 166 pp.

LONDON L, DE GROSBOIS S, WESSELING C, KISTING S, ROTHER HA and MERGLER D (2002) Pesticides usage and health consequences for women in developing countries: Out of sight, out of mind? Int. J. Occup. Environ. Health 8 46-59. https://doi. org/10.1179/oeh.2002.8.1.46

MACHETE F (2017) Environmental health risks associated with e-waste exposure in Badplaas, Carolina and Elukwatini landfills, Republic of South Africa. Afr. J. Sci. Technol. Innov. Dev. 9 (7) 679-684. https://doi.org/10.1080/20421338.2017.1355602

MAHARAJ S (2005) Modelling the behaviour and fate of priority pesticides in South Africa. MSc. dissertation, University of the Western Cape.

MCKINLAY R, PLANT JA, BELL JNB and VOULVOULIS N (2008). Endocrine disrupting pesticides: implications for risk assessment. Environ. Int. 34 168-183. https://doi.org/10.1016/j. envint.2007.07.013

NAIDOO V and BUCKLEY CA (2003) Survey of pesticide wastes in South Africa and review of treatment options. WRC Report No. 1128/1/03, Water Research Commission, Pretoria.

SCHULZ R (2001) Rainfall-induced sediment and pesticide input from orchards into the Lourens River, Western Cape, South Africa: importance of a single event. Water Res. 35 1869-1876. https://doi. org/10.1016/S0043-1354(00)00458-9

STATS SA (Statistics South Africa) (2016) Community Survey 2016: Statistics release, P0301. URL: http://cs2016.statssa.gov. za/wp-content/uploads/2016/07/NT-30-06-2016-RELEASEfor-CS-2016-_Statistical-releas_1-July-2016.pdf(Accessed 8 August 2016). 